\title{
SELECTING ENTERPRISE APPLICATIONS FOR CURRICULUM: INSIGHTS FROM A TEACHING INITIATIVE
}

\author{
Jae J. Choi, Pittsburg State University, jchoi@pittstate.edu \\ Thomas L. Ngo-Ye, Alabama State University, tngoye@alasu.edu
}

\begin{abstract}
Many schools incorporate hands-on labs of Enterprise Applications into Management Information Systems (MIS) curricula. Instructors can be overwhelmed with a variety options including Enterprise Resource Planning (ERP), Supply Chain Management (SCM), Customer Relationship Management (CRM), and Business Intelligence (BI) just to name a few. To complicate matters further, there are a number of viable vendors for each option. The current study aims to offer insights and share experiences of vendor selection, contracting, and product selection procedures. Eventually, the current study illustrates the effectiveness of selected applications for general MIS education.
\end{abstract}

Keywords: Enterprise Applications, ERP, SCM, CRM, SAP, Business Intelligence, Data Analytics

\section{INTRODUCTION}

Enterprise Applications such as ERP and CRM have been adopted as a vehicle to mitigate information silo problems and integrate business functions (Kroenke \& Boyle, 2016). As it has brought in improved user productivity, effectiveness, and internal efficiency (Lotfy \& Halawi, 2015), skills relevant to Enterprise Applications are considered critical for new college graduates (Dunaway, 2015). A study demonstrated that students with practical experiences in Enterprise Applications have a clear advantage in the job market (Chen \& Lee, 2013). It is not surprising that many schools are incorporating Enterprise Applications into their curricula to better prepare their graduates with marketable skills (Dunaway, 2015).

Paradoxically, however, studies found that only a small fraction of instructors at adopted institutions provide handson exercises due to the time consuming set-up procedure, the lack of step-by-step instruction materials, and the lack of motivation especially at research universities (Chen \& Lee, 2013). These issues were taken seriously in each step of our adoption procedure.

The current study aims to share our experiences in the procedure of adopting and incorporating Enterprise Applications into Computer Information Systems (CIS) curricula. It involves a variety of topics relevant to strategic visioning, curriculum renovation, contracting, and contents development. Special focus is drawn on the procedure of selecting optimal combination of products to be utilized in class lab activities.

\section{DECISION TO INCORPORATE ENTERPRISE APPLICATIONS}

The CIS degree program at one of the authors' school used to offer two emphases, namely, System Design and Information Assurance. System Design track reflects the legacy of computer science program, which was discarded years ago. However, its core courses still include Software Engineering, Operating Systems, and a variety of programming languages. The main challenge is that its graduates are not equipped with skills necessary to favorably compete against computer science graduates in the job market primarily due to the lack of proper computer related credits (CIS majors are required to take much more business core (42 credit hours) than CIS core (15 credit hours)). Hence, employers were not considering our CIS graduates the prime candidates for developer positions. On the other hand, Information Assurance track had its own set of challenges as well. With just one dedicated faculty member, the track couldn't offer more than two security courses beyond CIS core (i.e. Information Assurance and Computer Security Part 1 and 2). The part 1 course mainly addressed the overview of discipline and managerial aspect of computer security while the part 2 focused on application security (authentication for web programming and a set of 


\section{Issues in Information Systems}

Volume 20, Issue 1, pp. 195-203, 2019

threats like Cross Site Scripting attack, SQL injection, etc.). Obviously, more dedicated courses were needed to prepare students for the specialized areas. However, it wasn't a viable option considering the dwindling enrollment and limited faculty capacity.

Department of CIS conducted a SWOT analysis to overhaul its curricula. Two threats were identified. First, College of Technology is about to launch a new degree program of either Computer Engineering or Computer Science. Although the details of the program were not revealed at that time, it was obvious that most courses in System Analysis emphasis could be overshadowed once the new program were fully launched. Second, graduates from both tracks were not considered competitive in the job market. This partially stemmed from the weaknesses of both tracks identified above. CIS department considered multiple strategic options to become leaner, more nimble, and more competitive utilizing "Choose and Focus" strategy. First, it was considered to offer a single emphasis and beef up the System Design emphasis by expanding upper level programming courses utilizing the resources originally intended for Information Assurance emphasis. However, the program would still face direct competition from computer science programs within and out of campus. CIS students would have an uphill battle as long as 42 credit hours of business core are required to be taken. Eventually, CIS department decided to adopt mainstream MIS curricula to differentiate it from competitors and produce much demanded data scientists and business process specialists. The obvious starting point was choosing a proper vendor of Enterprise Applications, which would be embedded in classroom lab activities.

\section{VENDOR SELECTION}

Two viable options are available in the market. First, SAP, a global market leader in ERP offers SAP University Alliances (UA). It is a well-established program for higher education, offering Enterprise Applications hosting service through University Competence Centers (UCC). SAP partnered with institutions of higher education to establish six UCCs across the globe. They are located at Beijing Jiatong University, China, California State University, Chico, Magdeburg University, Germany, Queensland University of Technology, Australia, Munich Technical University, Germany, and University of Wisconsin, Milwaukee. UCCs provide lecture-specific educational offerings that instructors can customize for their own teaching or research goals. Instructors at UA member institutions do not require knowledge and staff for the installation and maintenance of SAP systems. However, UCC hosting service does not come free (annual cost of US\$ 8,000 for US institutions).

Through SAP UA program, member schools have free access to faculty training boot camps and shared curriculum contents (Hayen, 2015). Summer boot camps are usually hosted at University of Wisconsin-Milwaukee while Sam Houston state university hosts winter boot camps. A variety of topics are covered including SAP ERP Sales and Distribution (SD) module, ERP configuration, SAP BW (Business Warehouse), SAP Analytics Cloud, and ERPSim to name a few. However, popular topics like CRM or SCM tools are not usually covered. Likewise, just a few modules of ERP are discussed at the boot camps. An extensive set of teaching resources are shared through SAP Learning Hub, a SAP's digital medium of online education and data repository. A diverse contents including PowerPoint slides or step-by-step hands-on instruction for labs are available although their quality can be sporadic. The main criticism on the most shared lab instructions is that they are merely mouse-clicking exercises and students concentrate on finishing lab assignments as fast as possible without deep understanding (Hingorani, Beasley, \& Bradford, 2015).

Another option is Microsoft, one of the major Enterprise Applications vendor. Microsoft's ERP product is mainly adopted in manufacturing industry and enjoys more popularity in European countries (Kroenke \& Boyle, 2016). Microsoft offers very capable CRM and general ledger software as well (Kroenke \& Boyle, 2016). Microsoft's answer to SAP UA is Microsoft Dynamics Academic Alliance (DynAA), which offers free access to faculty training workshops. Since no hosting service is available directly from Microsoft or its partners, member schools are left with the following possible options (Ngo-Ye, 2016). First, some institutions decide to maintain and host the system inhouse. Of course, additional labor cost may be incurred. Second, other institutions outsource hosting service elsewhere. This is technologically identical solution to SAP UA. Only difference is that hosting companies do not have any relationship with Microsoft or DynAA. Hosting service cost should be equivalent to SAP UCCs.

Considering the maturity of SAP's UA program, and quality of standardized hosting service, CIS department decided to explore partnership with SAP. 


\section{Issues in Information Systems \\ Volume 20, Issue 1, pp. 195-203, 2019}

\section{CONTRACTING}

SAP UA offers two levels of membership, namely associate membership and full membership. As associate membership does not come with hosting service, it is completely free with all the other privileges of full membership except hosting. Initially, CIS department decided to evaluate the benefits of SAP UA through associate membership considering the significant commitment and annual hosting cost involved (April, 2018). The contract procedure for associate membership was rather straightforward. Once the required data sheet was filed, a copy of contract was delivered for review and signing. University's general counsel designated business dean as signatory authority and conducted legal review. Two faculty volunteers participated the summer faculty boot camps at University of Wisconsin-Milwaukee in July, 2018 and reported their positive impression on the quality of training and shared teaching materials.

In the meantime, CIS department continuously worked on overhauling its program. Two legacy tracks converged to form a single information systems emphasis where data analytics and business processes play a larger role. New courses like "Advanced Database" and "Data Analytics and Business Intelligence" were rapidly legislated while course contents were being developed by one of SAP Summer faculty boot camps participants. The instructor assigned to teach those courses enrolled in SAP Analytics Cloud and SAP Predictive Analytics. The contents utilizing SAP Predictive Analytics were quickly adopted in "Data Analytics and Business Intelligence" in the following fall semester when the new course was launched.

The other faculty participant at the summer faculty boot camps went for sabbatical leave at University of WisconsinMilwaukee (Fall, 2018), one of two North American UCCs. He went through further training for a variety of SAP Enterprise Applications and developed course contents with the help of hosting faculty members. Further, he initiated and oversaw the contracting procedure for the full membership once joining the full membership was decided. The target date for full membership was January 1st, 2019.

After the agreement between the Candidate University and SAP is finalized, one of two North American UCCs are assigned to the applicant. The second phase of contracting is initiated by the UCC. Since modifications of contract wordings were requested from the University's General Counsel and UCC during the procedure, the completion of contracting was much delayed than expected. However, product request to UCC was readily available right before the following spring semester in January, 2019.

\section{COURSES AND CONTENTS}

Initially, SAP Predictive Analytics was adopted as a primary application in "Data Analytics and Business Intelligence" course mainly due to training the instructor received at SAP faculty boot camps in 2018. The instructor is considering more applications like SAP Analytics Cloud and SAP BW for fall semester, 2019 after returning from the relevant boot camps in summer, 2019. SAP Analytics Cloud is the most advanced cloud-based analytics solution, featuring all the analytics capabilities like Business Intelligence, planning, and predictive analytics in a single solution (SAP, 2019) although it needs to improve a certain functionalities like data shaping and blending (Douglas, 2017). SAP BW is a massive scale business warehouse which is fully integrated with SAP Analytics Cloud and a fundamental basis for a variety of analytic operations including data mining and machine learning.

On the other hand, the development of courses in business processes is still ongoing. Various courses are currently considered including Supply Chain Management (using SAP SCM), Consumer Relationship Management (using SAP CRM), Accounting Information Systems (using SAP S/4 HANA's accounting module), Introduction to Business Processes (using SAP S/4 HANA), ERP Configuration (using SAP S/4 HANA), and Strategic Management (using ERPSim). As the considered courses span diverse disciplines from CIS to Accounting to Marketing to Management, it was decided to introduce a combination of different Enterprise Applications at a business core course which all the business major students are required to take. The purpose is twofold: to prepare students for the advanced SAP classes (which will be available in the future) in their own discipline, and to expose them the business processes in other disciplines. CIS 420 Management Information Systems (MIS) course was chosen for the purpose as it is a business core to provide business major students with an overview of MIS. 


\section{Issues in Information Systems}

Volume 20, Issue 1, pp. 195-203, 2019

The MIS course is designed to feature different components to deliver an overview of MIS. It consists of DevOps, ERP, Data Analytics, Database, and a term project involving web development and interface mock-up design. The components where SAP platform can be applied include ERP, Data Analytics, Database, and the web development project.

First, different modules of SAP S/4 HANA were considered for ERP component; FI (Financial Accounting), CO (Controlling), SD (Sales and Distribution), HCM (Human Capital Management), PP (Production Planning), MM (Material Management), and QM (Quality Management). Three modules like FI, SD, and MM were primarily considered because they were covered in the faculty boot camp for introductory business processes. However, as the College of Business does not offer a major or relevant courses in production management, MM was immediately discarded from the candidate list.

Other Enterprise Applications such as SCM and CRM were considered as a logistics faculty and a marketing faculty expressed their interests in developing relevant courses. SCM is an advanced planning engine and is able to meet the complex supply chain challenges in Demand Planning, Supply Chain Planning, Production Planning and detailed Scheduling, Distribution Planning and Transport Planning (saponlinetutorials, 2019). CRM automates and integrates customer-facing activities like sales, marketing, and customer service, providing additional tools for customer analytics, personalization, e-commerce, social media, collaboration, and more (SAP, 2019). Course materials for both SCM and CRM are readily available through Learning Hub.

ERPSim is not a part of SAP Enterprise Applications. It is a business simulation game developed by HEC Montreal for SAP S/4 HANA in which participants use a real ERP system to manage their virtual company in a competitive market (ERPsimLab, 2019). As ERPSim is a popular business simulation platform and widely used for Strategic Management or Marketing education, it was a strong candidate to be offered. It is not surprising that two levels of faculty boot camps (introductory and advanced) are offered each and every year. However, ERPSim was discarded from the list of initial offerings due to the following reasons; the lack of training (can be addressed in summer, 2019) and the extra cost incurred to students (SAP UCC does not charge extra for hosting ERPSim system. However, all but the basic game cost each student).

SAP Predictive Analytics was selected for Data Analytics, the second component, as it features an easy-to-use data visualization functionalities. More advanced features utilizing SAP Analytics Cloud are desirable for advanced courses like "Data Analytics and Business Intelligence". SAP BW can be used for the next component, database. However, the topics involving data warehousing with advanced data analytics tools mandate prerequisite knowledge. Since most students in the MIS course do not have background in database, it was decided to adopt Microsoft Access instead in order to address basic notions of relational database.

Finally, SAP interface programming can be considered for the term project involving web development and interface mock-up design. Users of SAP systems can develop mobile apps interfaces for SAP systems, utilizing SAP system interfaces. Although it is a fascinating topic, students outside of CIS department are not prepared for such a task. Hence, popular web builder tools and mock-up tools (instead of SAP interface programming) were adopted for the term project.

In sum, SAP S/4 HANA modules like FI and SD, SAP Enterprise Applications such as SCM and CRM, and SAP Predictive Analytics were included in the list of initial offerings for the MIS course. Step-by-step lab tutorials for each application are readily available through faculty boot camps and Learning Hub. For an instance, exercises for SD module are available for different user interfaces and versions including Fiori and SAP GUI. As the expected completion time is three to four hours (can be translated into 3 to 4 weeks if one hour lab is assigned each week), lab exercises were modified to be finished in a couple of weeks.

The discussion is summarized in Table 1 and 2. 
Table 1. Courses Currently Using SAP Products

\begin{tabular}{|l|l|l|l|}
\hline \multicolumn{1}{|c|}{ Courses } & \multicolumn{1}{|c|}{ Adopted SAP Product } & \multicolumn{1}{c|}{ Considered } & \multicolumn{1}{c|}{$\begin{array}{c}\text { Weight of } \\
\text { SAP Lab }\end{array}$} \\
\hline $\begin{array}{l}\text { Data Analytics and } \\
\text { Business Intelligence }\end{array}$ & SAP Productive Analytics & $\begin{array}{l}\text { SAP Analytics Cloud, } \\
\text { SAP BW }\end{array}$ & $50 \%$ \\
\hline $\begin{array}{l}\text { Management Information } \\
\text { Systems }\end{array}$ & $\begin{array}{l}\text { SAP S/4 HANA Modules (FI, SD), SCM, } \\
\text { CRM, SAP Productive Analytics }\end{array}$ & $\begin{array}{l}\text { SAP S/4 HANA } \\
\text { Modules (MM) }\end{array}$ & $50 \%$ \\
\hline
\end{tabular}

Table 2. Courses under Development

\begin{tabular}{|l|l|}
\hline \multicolumn{1}{|c|}{ Courses } & \multicolumn{1}{c|}{ Considered SAP Product } \\
\hline Supply Chain Management & SAP SCM \\
\hline Accounting Information Systems & SAP S/4 HANA Accounting Modules \\
\hline Strategic Management & ERPSim \\
\hline ERP Configuration & SAP S/4 HANA \\
\hline
\end{tabular}

\section{OPERATIONS AND ADMINISTRATION}

Each member institution has a designated person as the faculty coordinator, who provides a liaison with the member institution and UA North American team. More importantly, the faculty coordinator is the first line of help with installing SAP GUI, registering for UCC and Learning Hub access, downloading curriculum, and resolving any possible questions by campus faculty (SAP UA, 2011).

Initially, all faculty who are using SAP software in the classroom need to register on the UCC website and fill in their profile. Once faculty members go to the web site provided by the UCC, they need to click on the "Register" tab located in the upper right hand corner of the home screen (as depicted in Figure 1).

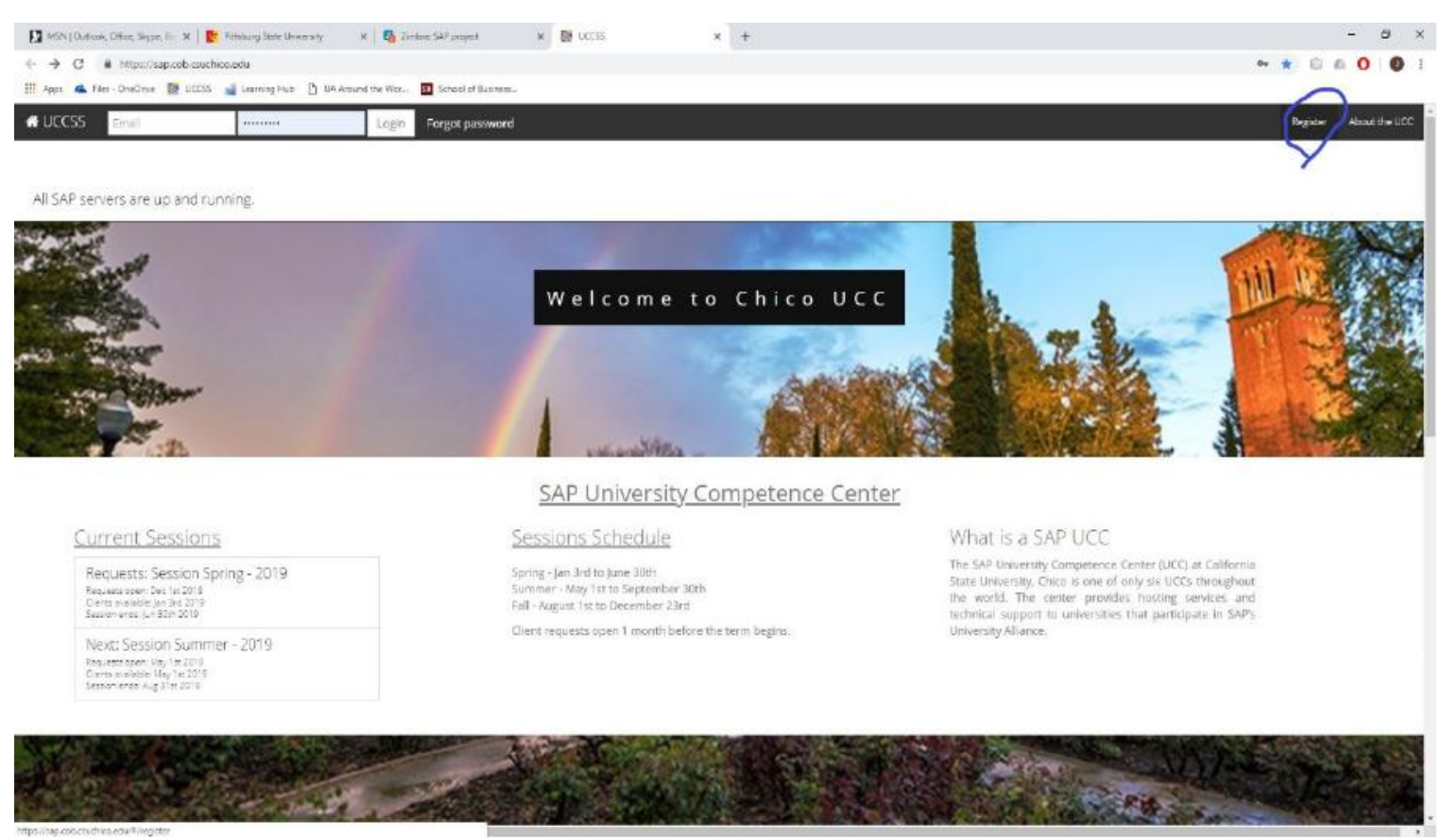

Figure 1. UCC Web Interface for Homepage 


\section{Issues in Information Systems}

Volume 20, Issue 1, pp. 195-203, 2019

Once "Register" tab is clicked, faculty members are directed to a screen where they can create a new account as shown in Figure 2.

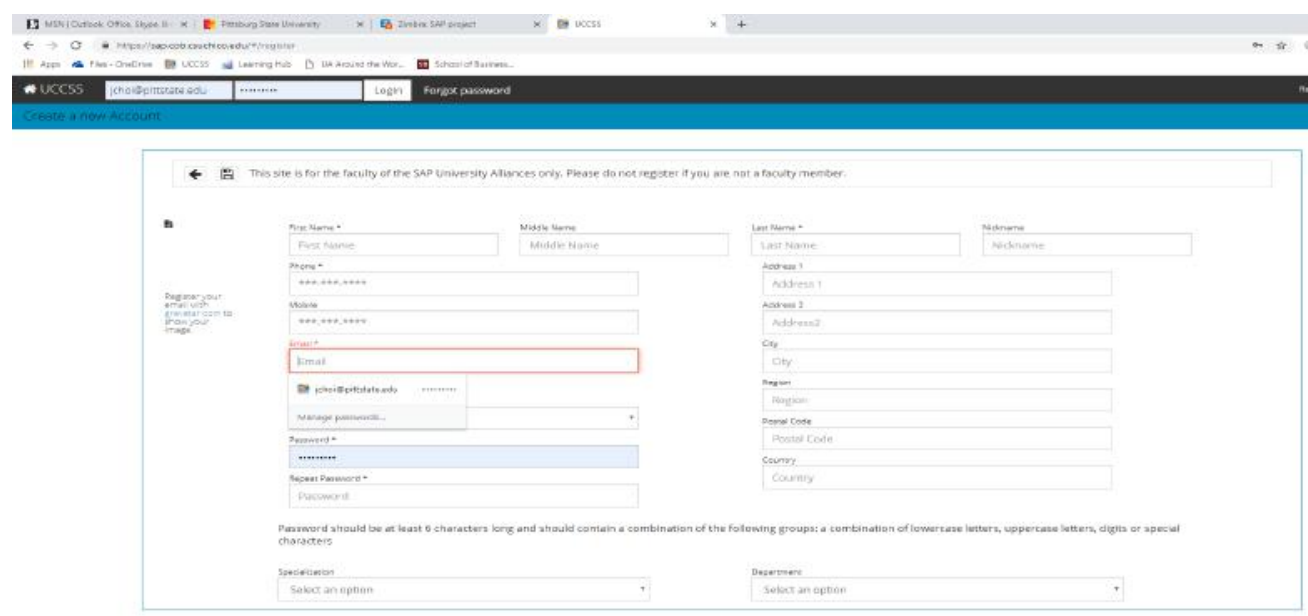

Figure 2. UCC Web Interface for Account Creation

After the account is created, an email is generated and sent to the faculty coordinator for approval. Once the faculty coordinator approves the request, they will have access to the SAP UCC website and may participate in SAP hosting services. To request a client, select the "Product Request" tab, choose the "Create Request" tab, and choose proper options from the dropdown lists. The interface is depicted in Figure 3.

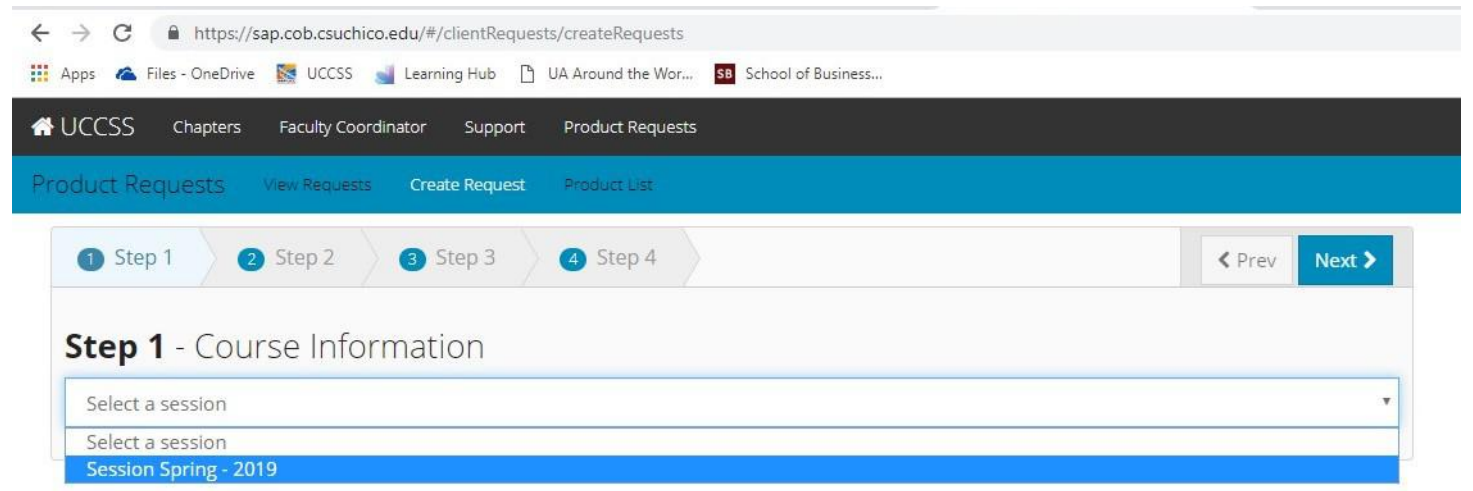

Figure 3. UCC Web Interface for Client Request

It is important to note that UCC hosts no more than seven SAP clients during each academic term according to SAP UA Program End User Agreement. Client refer to a single instance of SAP defined by a client number and containing the data to run the software.

\section{OUTCOMES AND DISCUSSION}

Standard module cases studies from Learning Hub were utilized. PDF copies are readily available upon request. Although lab activities for the period of ten weeks were prepared for SAP S/4 HANA modules (FI and SD), SAP SCM and CRM, and SAP Predictive Analytics, both SD and CRM couldn't be covered due to multiple unexpected events like inclement weather or lab availability issues. A set of survey questions was prepared and distributed in order to measure the perceived effectiveness of SAP software utilized in lab activities (evaluation period is Spring, 
2019). A comparison was made between the utilized software and others (either selected but not used or not selected from the first place). The survey questionnaire instruments are presented in the Appendix.

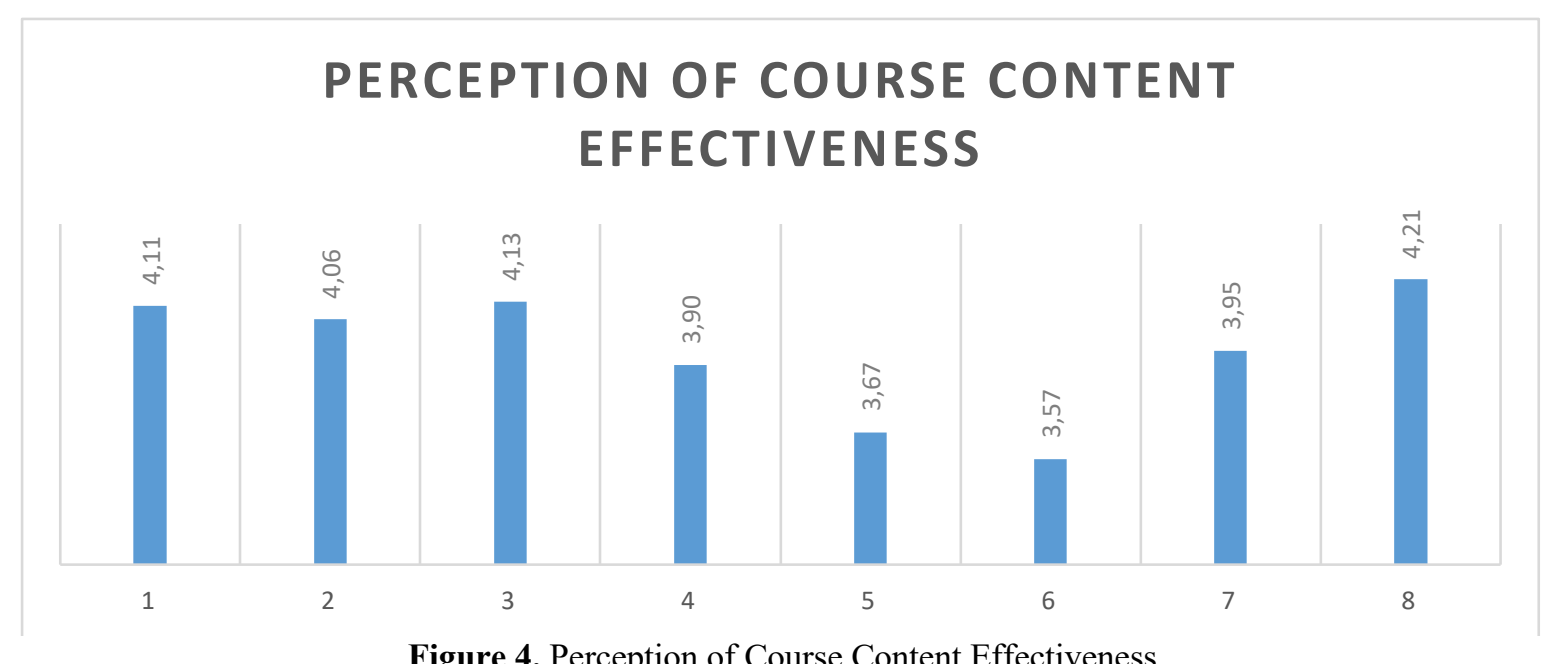

Figure 4. Perception of Course Content Effectiveness

Figure 4 summarizes what we found from the survey. Question 1 (SAP Predictive Analytics), 2 (SD), and 3 (SCM) concern the effectiveness of SAP software used in the course while question 4 (CRM), 5 (MM), 6 (FI), 7 (SAP BW), and 8 (ERPSim) are about the effectiveness of SAP software not utilized in the course. More specifically, question 4 and 6 address the SAP software which was adopted but not used due to unexpected reasons. Question 5 and 7 concern items not considered from the beginning. Question 8 addresses ERPSim, which was discarded due to the cost incurred to students. Answers range from 1 to 5 ( 1 indicates non-effective and 5 signifies most effective). 4 and above suggest strong indication of effectiveness.

Table 3. Effectiveness for Each Group

\begin{tabular}{|c|c|c|}
\hline Group & \multicolumn{2}{|c|}{ Average Response } \\
\hline Adopted and used & 4.10 & \multirow{4}{*}{3.86} \\
\hline Adopted but not used & 3.74 & \\
\hline Not adopted due to a variety of reasons & 3.81 & \\
\hline Not adopted due to cost issue & 4.21 & \\
\hline
\end{tabular}

Overall, students perceived that the SAP software utilized for lab activities were quite effective to learn concepts relevant to MIS (4.10). Table 3 suggests that the average effectiveness of adopted and used SAP software (4.10) is slightly better than what is not utilized (3.86). The products not adopted due to a variety of reasons were reported even less effective than overall average of non-utilized products (3.81). Another remarkable observation is that CRM and FI (adopted but not used eventually) marked the lowest score. One possible explanation is that students were distracted by the complexity of involved business processes in FI. In fact, the perceived effectiveness of FI was the lowest among all the products surveyed (3.57). Another finding suggests that ERPSim needs to be reconsidered for adoption given the perceived preference of ERPSim (4.21). ERPSim scored the highest among the reported products. A possible drawback of these findings could stem from students' inexperience of non-utilized products surveyed. To mitigate this potential issue, we got students exposed to a few elementary activities involving the non-utilized products before implementing this survey. For the products which weren't requested for spring, 2019, we had students watch the tutorial video clips available online.

\section{FUTURE PLANS AND CONCLUDING REMARKS}

The current study attempted to contribute to knowledge bases, documenting the procedure of strategic visioning, curriculum renovation, and contents development. Particularly, we focused on the detailed procedures of incorporating Enterprise Applications into curricula, including Enterprise Application vendor selection (based on a variety of criteria 


\section{Issues in Information Systems}

Volume 20, Issue 1, pp. 195-203, 2019

such as options for teaching materials, training availability, cost, etc.), contracting procedures (for associate and full membership for SAP UA), operating procedures (involving the role of faculty coordinator), and most importantly, procedure of choosing optimal combination of products utilized in class lab activities. During the later weeks of the semester, a set of survey instruments were developed and distributed to elicit students' perception on the utilized products and candidate products for subsequent semesters. The results clearly indicate that the initial offerings were successful in delivering adequate values to students. Different sets of combinations are being prepared to be compared with the current offerings. Subsequent studies in upcoming semesters are planned to report our continuous effort for improvement.

\section{REFERENCES}

Chen, K. L., \& Lee, H. (2013). Using Microsoft Dynamics CRM for business process management: A curriculum package for business process management or supply chain management courses. Journal of Integrated Enterprise Systems, 2(1), 44-79.

Douglas, P. (2017, July 13). SAP Predictive Analytics vs. SAP Analytics Cloud-demo. Retrieved April 29, 2019, from bluefinsolutions.com: https://www.bluefinsolutions.com/insights/peter-douglas/july-\%60/sapanalytics-cloud-2-sap-predictive-analytics-v

Dunaway, M. (2015). Teaching case: A situated learning approach to ERP role adaptation and business intelligence. Issues in Information Systems, 16(2), 195-208.

ERPsimLab. (2019). ERPsim, the Business Simulation for SAP S/4HANA. (ERPsim Lab, HEC Montréal) Retrieved April 29, 2019, from erpsim.hec.ca: https://erpsim.hec.ca/en/erpsim

Hayen, R. (2015). Structured assignment pedagogy: An SAP enterprise software deployment. Issues in Information Systems, 16(2), 17-26.

Hingorani, K., Beasley, B., \& Bradford, J. (2015). Enhancing student learning of ERP configuration through a Quickbooks tutorial. Issues in Information Systems, 16(1), 132-141. Retrieved May 28, 2016, from http://www.iacis.org/iis/2015/1_iis_2015_132-141.pdf

Kroenke, D. M., \& Boyle, R. J. (2016). Experiencing MIS (7th ed.). Upper Saddle River, New Jersey, U.S.A.: Pearson.

Lotfy, M., \& Halawi, L. (2015). A Conceptual model to measure ERP user-value. Issues in Information Systems, $16(3), 54-63$.

Ngo-Ye, T. L. (2016). Introducing Practical Hands-on ERP Labs into Curriculum: Two Cases of Junior Faculty Championing ERP Teaching Initiatives. Journal of Integrated Enterprise Systems, 4(1), 31-43. Retrieved April 30, 2019, from http://clcloud.com/jies/V4N1/J021JIESV4N1.pdf

SAP. (2019). SAP Analytics Cloud. Retrieved April 30, 2019, from SAP: https://www.sap.com/products/cloudanalytics.html

SAP UA. (2011). Role of the Faculty Coordinator.

saponlinetutorials. (2019). SAP SCM (Supply Chain Management) Modules. Retrieved April 30, 2019, from saponlinetutorials: https://www.saponlinetutorials.com/sap-scm-supply-chain-management-modules/ 


\section{APPENDIX}

\section{Student Perception of Course Content Effectiveness}

Statement of Purpose

The purpose of this survey is to provide the instructor with your feedback on your experience with lab activities included in CIS 420 Management Information Systems. Your voluntary participation is of vital importance to the quality of this course in the future.

1. SAP Predictive Analytics lab seems to be an effective content to learn Management Information Systems.
A. Strongly disagree
B. Disagree
C. Undecided
D. Agree
E. Strongly agree

2. SAP ERP SD (Sales Distribution) lab seems to be an effective content to learn Management Information Systems.
A. Strongly disagree
B. Disagree
C. Undecided
D. Agree
E. Strongly agree

3. SAP SCM (Supply Chain Management) lab seems to be an effective content to learn Management Information Systems.
A. Strongly disagree
B. Disagree
C. Undecided
D. Agree
E. Strongly agree

4. I'd like to see a SAP CRM (Customer Relationship Management) in the future list of hands-on labs.
A. Strongly disagree
B. Disagree
C. Undecided
D. Agree
E. Strongly agree

5. I'd like to see a SAP ERP Manufacturing module in the future list of hands-on labs.
A. Strongly disagree
B. Disagree
C. Undecided
D. Agree
E. Strongly agree

6. I'd like to see a SAP ERP Financial Accounting module in the future list of hands-on labs.
A. Strongly disagree
B. Disagree
C. Undecided
D. Agree
E. Strongly agree

7. I'd like to see a SAP Business Intelligence in the future list of hands-on labs.
A. Strongly disagree
B. Disagree
C. Undecided
D. Agree
E. Strongly agree

8. I'd like to see a business simulation game (where participants use a real ERP system to manage their virtual companies) in the future list of hands-on labs.
A. Strongly disagree
B. Disagree
C. Undecided
D. Agree
E. Strongly agree 